\title{
Preliminary evidence of discourse improvement with dopaminergic medication
}

\author{
Janelle Sanchez ${ }^{1}$, Kristie A. Spencer ${ }^{2 *}$ \\ ${ }^{1}$ Department of Physical Medicine \& Rehabilitation, MultiCare Good Samaritan Hospital, Puyallup, USA \\ ${ }^{2}$ Department of Speech and Hearing Sciences, University of Washington, Seattle, USA; *Corresponding Author: kas@uw.edu
}

Received 16 November 2012; revised 28 December 2012; accepted 10 January 2013

Copyright (C) 2013 Janelle Sanchez, Kristie A. Spencer. This is an open access article distributed under the Creative Commons Attribution License, which permits unrestricted use, distribution, and reproduction in any medium, provided the original work is properly cited.

\begin{abstract}
Dopaminergic therapy can improve motor functioning in Parkinson's Disease (PD), but its effect on spoken discourse is poorly understood. This study addressed whether discourse produced during a one-minute monologue would be affected by medication withdrawal. We performed a detailed analysis of semistructured speech samples in 38 patients with PD, including measures of efficiency, syntactic complexity, cohesion (i.e., lexical and grammatical ties between sentences), and coherence (i.e., semantic relationship between the utterances and the topic, or between utterances). We found that patients produced more efficient and coherent monlogues when on versus off medication. As discourse relies heavily on cognitive processes such as working memory, these findings are consistent with research showing improved working memory and executive processes with dopaminegic medication.
\end{abstract}

Keywords: Dopaminergic Therapy; Discourse; Language; Speech; Parkinson's Disease

\section{INTRODUCTION}

The effect of Parkinson's Disease (PD) on language, particularly spoken discourse, is not well understood. Much of the extant research has focused on single word or sentence level production and comprehension tasks. Less studied is how PD affects discourse, even though it is an essential component of day-to-day communication. Discourse appears to depend largely on higher-level executive processes and working memory [1] which are mediated by circuits connecting the basal ganglia, thalamus, and prefrontal cortical areas and are often impaired in individuals with PD [2,3]. The few discourse studies to date report a trend toward decreased informational content as well as decreased complexity of syntax [4-6]. Others report no abnormalities with narrative production in non-demented individuals with PD [7]. These observations are difficult to interpret due to the limited and variable nature of studies to date. Investigations have differed in terms of the disease stage of participants, inclusion criteria (especially regarding dementia status), and the level of description of participants, including presence and severity of dysarthria. Moreover, no known studies have controlled for the effects of dopaminergic medications on discourse, making it difficult to distinguish whether language performance in these studies is modulated by disease effects or medication.

The intent of the present study was to examine the effects of medication status on discourse in PD. It was hypothesized that medication withdrawal would have a negative impact on all discourse outcomes, including measures of efficiency, syntactic complexity, cohesion (i.e., lexical and grammatical ties between sentences), and coherence (i.e., semantic relationship between the utterances and the topic or between utterances). This hypothesis was based on the assumption that, without medication, levels of dopamine in the striatum are insufficient for optimal cognitive functioning even in mild PD. Conversely, restoration of dopamine levels in the basal ganglia would facilitate the cognitive skills subserving discourse, such as working memory, planning, and inhibition of competing alternatives $[8,9]$. Working memory in particular has been associated with discourse measures such as cohesion, narrative organization, and syntax measures in patients with closed head injury [10]. Quantity of spoken output was not anticipated to change with medication state $[11,12]$. 


\section{METHODS}

\subsection{Participants}

The present study was approved by the Institutional Review Board of the University of Washington. All participants gave their written informed consent. Participants included 38 adults ( 24 male, 14 female) with idiopathic Parkinson's Disease who were recruited from local support groups or outpatient clinics. Age ranged from 41 to 87 years $(M=67.4, S D=9.3)$, level of education ranged from 12 to 23 years $(M=16.8, S D=2.6)$, and years post $\mathrm{PD}$ diagnosis ranged from 6 months to 22 years $(M=5.9, S D=5.1)$. The majority of participants were functioning at Hoehn and Yahr Stages II and III [13]. All but two participants had the classic motor syndrome of PD without treatment-induced motor complications. All participants were native American English speakers with adequate hearing. Selection criteria for the participants with PD was as follows: 1) medically documented idiopathic PD per neurology records; 2) a minimum of six months post PD diagnosis; 3) receiving levodopa and/or dopamine agonist therapy; and 4) no history of other neurological illness, neurosurgical intervention, or psychiatric disorder. Seven participants were taking levodopa as their only form of pharmacological intervention. Twenty others were taking some combination of levodopa plus dopamine agonists, MAO inhibittors, COMT Inhibitors, anticholinergic agents or amantadine. In terms of speech function, seven participants were classified as having dysarthria, 16 participants had hypophonia with no other speech abnormalities, and the remaining 15 participants had no reported or observed speech involvement.

Participants needed to meet the following criteria: 1) absence of dementia as determined by a score above 24 on the Mini Mental State Exam [14]; 2) absence of moderate or severe depression as determined by a score less than 24 on the Beck Depression Inventory II [15]; 3) absence of receptive language deficits as determined by performance above the $85^{\text {th }}$ percentile on subtests of the Boston Diagnostic Aphasia Exam [16]; and 4) absence of phonological encoding difficulty as determined by scores above $85 \%$ on the Word Rhyme Judgments reading subtest of the Psycholinguistic Assessments of Language Processing in Aphasia [17].

\subsection{Procedures}

Participants provided a one-minute monologue on a topic of their choice during two separate sessions that occurred within a one week time period. Participants were given time to choose a topic before beginning their monologue, and were asked to speak until signaled to stop. All participants were prompted with the following instruction: "You can speak on any topic you desire, such as your family, your job, a trip you took, etc." Participants provided one language sample in the "on" medication state (i.e., 1 - 3 hours after their last dose) and one sample in the "off" medication state. The off state was defined as a withdrawal from all dopaminergic medications for at least 15 hours, as per criteria outlined in the Core Assessment Program for Surgical Intervention Therapies in Parkinson's disease (CAPSIT-PD) [18]. Samples were collected using an AKG, MicroMic Series III, C520 head worn microphone (with a constant mouthto-microphone distance of one inch) and a professional mobile digital recorder (KORG MR-100). Each language sample was orthographically transcribed from a digital recording and entered into the Systematic Analysis of Language Transcripts (SALT) [19] by two trained raters. Raters were blind to medication state. Utterances were segmented according to the "Communication Units" conventions of SALT, which are in alignment with procedures outlined by Glosser, Weiner, and Kaplan [20]. Thus, utterances consisted of one main independent clause plus any subordinate clauses.

The following dependent variables were evaluated for change with medication state: 1) quantity of discourse (words per minute); 2) efficiency of discourse (mazed words, i.e., filled pauses, false starts, repetitions, reformulations, and interjections); 3) abandoned utterances; 4) syntactic complexity (mean length of utterance in words excluding mazed words); 5) cohesion (based on the system developed by Halliday and Hasan [21] for identifying between-sentence cohesive ties); and 6) coherence (based on the system developed by Van Leer and Turkstra [22] for coding the relationship of each utterance to the general topic [global coherence] and to the previous utterance [local coherence]).

\section{RESULTS}

\subsection{Reliability}

Inter-rater reliability for $20 \%$ of SALT transcriptions ranged from $88.8 \%-97.4 \%$. Reliability of coherence and cohesion ratings was adequate and ranged from $82.9 \%$ $97.6 \%$. Intrajudge reliability for the primary rater for $20 \%$ of monologues ranged from $97.4 \%-99.2 \%$.

\subsection{Group Analyses}

Matched pair $t$-tests were used to assess differences between medication states (on versus off) for each discourse variable in the domains of quantity, efficiency, syntax, cohesion, and coherence. $p$-values were set at 0.05 ; all comparisons were motivated by a priori hypotheses, thus corrections for multiple comparisons were not performed [7]. Table 1 reports the group data for each of these variables. No significant group differences were found on measures of efficiency, syntax, cohesion, 
Table 1. Group performance on discourse measures on versus off dopaminergic medications.

\begin{tabular}{|c|c|c|c|c|c|c|}
\hline & Variable & & ON & OFF & t-value & $p$-value \\
\hline \multirow[t]{2}{*}{ Quantity } & Words/Min & Mean & 142.14 & 155.17 & -3.50 & $0.001^{*}$ \\
\hline & & SD & 30.92 & 35.14 & & \\
\hline \multirow[t]{4}{*}{ Efficiency } & \% Mazed Words & Mean & 7.00 & 6.45 & 0.95 & 0.347 \\
\hline & & $\mathrm{SD}$ & 3.70 & 3.89 & & \\
\hline & Abandoned Utterances & Mean & 0.11 & 0.05 & 0.81 & 0.422 \\
\hline & & SD & 0.31 & 0.23 & & \\
\hline \multirow[t]{2}{*}{ Syntax } & Mean length of utterance in words & Mean & 12.46 & 13.08 & 1.04 & 0.307 \\
\hline & & SD & 3.91 & 4.45 & & \\
\hline \multirow[t]{2}{*}{ Cohesion: } & Complete ties/ Total Ties & Mean & 0.88 & 0.90 & 0.46 & 0.645 \\
\hline & & SD & 0.19 & 0.12 & & \\
\hline (Referential, Conjuctive and & Complete Ties/Total Words & Mean & 0.09 & 0.10 & 0.84 & 0.405 \\
\hline \multirow[t]{3}{*}{ Lexical Ties between Sentences) } & & $\mathrm{SD}$ & 0.05 & 0.05 & & \\
\hline & Complete Ties/Utterance & Mean & 1.10 & 1.24 & 1.10 & 0.277 \\
\hline & & SD & 0.51 & 0.51 & & \\
\hline \multirow[t]{2}{*}{ Global Coherence: } & Global Coherence & Mean & 4.47 & 4.41 & -0.77 & 0.448 \\
\hline & & SD & 0.37 & 0.44 & & \\
\hline (Relationship of Monologue & $\%$ Global-definite relationship & Mean & 74.99 & 74.52 & -0.13 & 0.895 \\
\hline \multirow[t]{5}{*}{ to General Topic) } & & SD & 17.46 & 18.08 & & \\
\hline & $\%$ Global-possible relationship & Mean & 23.72 & 21.60 & -0.60 & 0.552 \\
\hline & & SD & 16.86 & 16.90 & & \\
\hline & $\%$ Global-no relationship & Mean & 1.29 & 3.71 & 1.92 & 0.063 \\
\hline & & SD & 3.10 & 7.55 & & \\
\hline \multirow[t]{2}{*}{ Local Coherence } & Local Coherence & Mean & 4.71 & 4.63 & -1.16 & 0.252 \\
\hline & & SD & 0.24 & 0.35 & & \\
\hline (Relationship of Statement to & \% Local-definite relationship & Mean & 85.88 & 82.65 & -1.17 & 0.248 \\
\hline \multirow[t]{5}{*}{ Previous Utterance) } & & SD & 10.97 & 12.86 & & \\
\hline & \% Local-possible relationship & Mean & 13.68 & 15.73 & 0.73 & 0.470 \\
\hline & & SD & 10.74 & 13.02 & & \\
\hline & $\%$ Local-no relationship & Mean & 0.44 & 2.50 & 2.26 & $0.03^{* *}$ \\
\hline & & SD & 2.70 & 4.68 & & \\
\hline
\end{tabular}

${ }^{*} p<0.01 ;{ }^{* *} p<0.05$.

and global coherence. However, participants with PD were found to differ significantly on versus off medication on a measure of local coherence (percent of utterances rated as having no relationship to the precedingutterance) $(t(37)=2.26, p=0.3)$. That is, participants produced fewer irrelevant utterances (were more cohe- rent) when they were medicated. In addition, a measure of global coherence (percent of utterances indicating no relationship to the general topic) approached significance $(t(37)=1.92, p=0.63)$, with participants again produc- ing fewer irrelevant utterances when on dopaminergic medications. In terms of the quantity of discourse, participants produced significantly fewer words per minute when they were on versus off medication $(t(37)=-3.50$, $p=0.01)$.

\section{DISCUSSION}

The purpose of the present study was to examine the effects of dopaminergic medication on spoken discourse 
in PD. Participants with PD performed significantly better on versus off medication on a measure of local coherence, demonstrating more of a connection between their utterances. In addition, group differences approached significance on a measure of global coherence, suggesting that medications may have increased the speakers' ability to maintain relevance to the topic of the monologue. While the effect of dopamine-replacement therapy on cognition is poorly understood, it may have differential effects on cognition [23]. Perhaps the cognitive processes thought to be enhanced by dopaminergic medications, such as working memory [24], support the higher-level online organizational components of discourse.

Previous research has not typically examined cohesion and coherence in PD, which are macro-level language analyses sensitive to discourse impairments in other populations with executive function and working memory deficits [10]. The exception is a study by Ash and colleagues [7] which found no significant impairments of narrative discourse in a group of 18 nondemented, individuals with PD; however, all participants were medicated when providing their narrative discourse sample. Other investigators $[4,5]$ did not examine cohesion/coherence, but did find deficits in discourse-level information content in individuals with PD.

While deficits in information content have been reported in individuals with $\mathrm{PD}$, measures of quantity have generally not differed between participants with PD and controls $[5,12,25,26]$. Thus, the finding that words per minute significantly decreased with medication was unexpected. The effect of medications on words per minute has been investigated by others. Most of these studies found that speech rate did not change with dopaminergic medication [27-29]. One possible explanation for the decreased speech output is that dopaminergic medications facilitate the basal ganglia's role in inhibiting irrelevant information [30,31]. This would cause an increase in the quantity of discourse when off medications without a similar increase in informativeness or relevance. Thus, the medications may have allowed participants to speak less, but with more salience. Similar to the improvement in coherence, the improved efficiency of discourse with medications may stem from improved planning $[32,33]$ and suppression of task-irrelevant responses [31] with increased dopamine in the dorsal striatum and prefrontal cortex. It is also supported by literature demonstrating improvements in working memory and executive functions with dopaminergic treatment [34-36]. These cognitive domains have been shown to correlate with discourse performance [10,37], and are likely important in formulating concise, relevant discourse.

It has been a matter of contention whether and to what extent observed changes in discourse in PD are attributable to dysarthria. While some researchers have implicated motor speech deficits in discourse performance [26], others have found only weak correlations between measures of motor speech and discourse impairment [5]. The results of the present study are in keeping with Murray's [5] contention that speech involvement in discourse performance is likely minimal. The majority of the sample that showed individual patterns of change on discourse on versus off medications did not have dysarthria. However, it is important to note that only those with mild dysarthria were represented in the current study. More severe motor speech impairment may have a greater impact on discourse measures.

In conclusion, we determined the discourse profile of patients with PD on versus off medication. Our sample consisted of patients with mild to moderate physical and cognitive impairment. We demonstrated that dopaminergic medication facilitates the production of more succinct and coherent utterances during production of monologues. Results also suggest that mild/moderate dysarthria does not influence the nature of discourse. Our findings fit with the notion that improved discourse may stem from enhanced cognitive functioning, such as improved working memory, with dopamine replacement therapy [34-36]. We have highlighted the need for continued, systematic investigation of the presence and origin of language impairment in PD, particularly with respect to discourse production. Such findings may help to elucidate the relationship between discourse function, cognitive abilities, disease severity, motor speech involvement, and dopamine-replacement therapy, and may lead to better prediction and management of individuals who experience discourse deficits with PD. This research will require sensitive outcome measures as well as a large enough sample to increase statistical power.

\section{ACKNOWLEDGEMENTS}

This work was partially supported by Grant 1-R03-DC007066 from the National Institute on Deafness and Other Communication Disorders to the second author. We are very grateful to all of the participants with Parkinson's disease and to Dr. Stacy Betz, Dr. Diane Kendall, Kristin France, Orli Shulein, Seth Hayden, Audra McAllen, Linda Saeb, Jillian Wood, and Kristin Rogan-Quigley.

\section{REFERENCES}

[1] Farag, C., Troini, V., Bonner, M., Powers, C., Avants, B., Gee, J., et al. (2010) Hierarchical organization of scripts: Converging evidence from fMRI and frontotemporal dementia. Cerebral Cortex, 20, 2453-2463. doi:10.1093/cercor/bhp313

[2] Crescentini, C., Mondolo, F., Biasutti, E. and Shallice T. 
(2008) Supervisory and routine processes in noun and verb generation in nondemented patients with Parkinson's disease. Neuropsychologia, 46, 434-447. doi:10.1016/j.neuropsychologia.2007.08.021

[3] Monetta, L., Grindrod, C. M. and Pell, M. D. (2008) Effects of working memory capacity on inference generation during story comprehension in adults with Parkinsons disease. Journal of Neurolinguistics, 21, 400-417. doi:10.1016/j.jneuroling.2007.11.002

[4] McNamara, P. and Durso, R. (2003) Pragmatic communication skills in patients with Parkinson's disease. Brain and Language, 84, 414-423.

doi:10.1016/S0093-934X(02)00558-8

[5] Murray, L.L. (2000) Spoken language production in Huntington's and Parkinson's diseases. Journal of Speech, Language, and Hearing Research, 43, 1350-1366.

[6] Portin, R., Laatu, S., Revonsuo, A. and Rinne, U.K. (2000) Impairment of semantic knowledge in Parkinson disease. Archives of Neurology, 57, 1338-1343. doi:10.1001/archneur.57.9.1338

[7] Ash, S., McMillan, C., Gross, R.G., Cook, P., Morgan, B., Boller, A., Dreyfuss, M., Siderowf, A. and Grossman, M. (2011) The organization of narrative discourse in Lewy body spectrum disorder. Brain \& Language, 199, 30-41. doi:10.1016/j.bandl.2011.05.006

[8] Cools, R. (2006) Dopaminergic modulation of cognitive function-implications for L-DOPA treatment in Parkinson's disease. Neuroscience and Biobehavioral Reviews, 30, 1-23. doi:10.1016/j.neubiorev.2005.03.024

[9] Zgaljardic, D.J., Borod, J.C., Foldi, N.S., Mattis, P.J., Gordon, M.F., Feigin, A., et al. (2006) An examination of executive dysfunction associated with frontostriatal circuitry in Parkinson's disease. Journal of Clinical and Experimental Neuropsychology, 28, 1127-1144. doi:10.1080/13803390500246910

[10] Youse, K.M. and Coelho, C.A. (2005) Working memory and discourse production abilities following closed-head injury. Brain Injury, 19, 1001-1009. doi:10.1080/02699050500109951

[11] Murray, L.L. and Stout, J.C. (1999) Discourse comprehension in Huntington's and Parkinson's diseases. American Journal of Speech Language Pathology, 8, 137148.

[12] Crucian, G.P., Huang, L., Barrett, A.M., Schwartz, R.L., Cibula, J.E., Anderson, J.M., et al. (2001) Emotional conversations in Parkinson's disease. Neurology, 56, 159-165. doi:10.1212/WNL.56.2.159

[13] Hoehn, M.M. and Yahr, M.D. (1967) Parkinsonism: Onset, progression and mortality. Neurology, 17, 427-442. doi:10.1212/WNL.17.5.427

[14] Folstein, M., Folstein, S. and McHugh, P. (1975) Minimental state: A practical method for grading the cognitive state of patients for the clinician. Journal Psychiatric Research, 12, 189-198. doi:10.1016/0022-3956(75)90026-6

[15] Beck, A.T., Steer, R.G. and Brown, G.K. (1996) Beck depression inventory. The Psychological Corporation, San Antonio.

[16] Goodglass, H. and Kaplan, E. (1976) The assessment of aphasia and related disorders. Lea \& Febiger, Philadelphia.

[17] Kay, J., Lesser, R. and Coltheart, M. (1992) Psycholinguistic assessment of language processing in Aphasia. Lawrence Erlbaum, Hove.

[18] Defer, G.L., Widner, H., Marie, R.M., Remy, P. and Levivier, M. (1999) Core assessment program for surgical intervention therapies in Parkinson's disease (CAPSITPD). Movement Disorders, 14, 572-584. doi:10.1002/1531-8257(199907)14:4<572::AID-MDS100 5>3.0.CO;2-C

[19] Miller J. and Chapman, R. (1985) Systematic analysis of language transcripts: User's manual. University of Wisconsin, Madison.

[20] Glosser, G., Wiener, M. and Kaplan, E. (1988) Variations in aphasic language behavior. Journal of Speech \& Hearing Disorders, 53, 115-124.

[21] Halliday, M.A.K. and Hasan, R. (1976) Cohesion in English. Longman, London.

[22] Van Leer, E. and Turkstra, L. (1999) The Effect of Elicitation task on discourse coherence and cohesion in adolescents with brain injury. Journal of Communication Disorders, 32, 327-49. doi:10.1016/S0021-9924(99)00008-8

[23] MacDonald, P.A., MacDonald, A.A., Seergobin, K.N., Tamjeddi, R., Ganjavi, H., Provost, J.-S. and Monchi, O. (2011) The effect of dopamine replacement therapy on ventral dorsal striatum-mediated cognition in Parkinson's disease: Support from functional MRI. Brain, 134, 14471463. doi:10.1093/brain/awr075

[24] Torta, D.M.E., Castelli, L., Zibetti, M., Lopiano, L. and Geminiani, G. (2009) On the role of dopamine replacement therapy in decision-making, working memory, and reward in Parkinson's disease: Does therapy dose matter? Brain and Cognition, 71, 84-91. doi:10.1016/j.bandc.2009.04.003

[25] Murray L.L. and Lenz L.P. (2001) Productive syntax abilities in Huntington's and Parkinson's diseases. Brain and Cognition, 46, 213-219. doi:10.1016/S0278-2626(01)80069-5

[26] Illes J., Metter E.J., Hanson W.R. and Iritani S. (1988) Language production in Parkinson's disease: Acoustic and linguistic considerations. Brain and Language, 33, 146160. doi:10.1016/0093-934X(88)90059-4

[27] De Letter, M., Santens, P., De Bodt, M., Boon, P. and Van Borsel, J. (2006) Levodopa-induced alterations in speech rate in advanced Parkinson's disease. Acta Neurologica Belgica, 106, 19-22.

[28] De Letter, M., Santens, P., Estercam, I., Van Maele, G., De Bodt, M., Boon, P. and Van Borsel, J. (2007) Levodopa-induced modifications of prosody and comprehensibility in advanced Parkinson's disease as perceived by professional listeners. Clinical Linguistics \& Phonetics, 21, 783-791. doi:10.1080/02699200701538181

[29] Goberman, A., Coelho, C. and Robb, M. (2005) Prosodic characteristics of Parkinsonian speech: The effect of Levodopa-based medication. Journal of Medical SpeechLanguage Pathology, 13, 51-68. 
[30] Cropley, V.L., Fujita, M., Innis, R.B. and Nathan P.J. (2006) Molecular imaging of the dopaminergic system and its association with human cognitive function. Biological Psychiatry, 59, 898-907. doi:10.1016/i.biopsych.2006.03.004

[31] Fera, F., Nicoletti, G., Cerasa, A., et al., (2007) Dopaminergic modulation of cognitive interference after pharmacological washout in Parkinson's disease. Brain Research Bulletin, 74, 75-83.

doi:10.1016/j.brainresbull.2007.05.009

[32] Cools, R., Stefanova, E., Barker, R.A., Robbins, T.W. and Owen, A.M. (2002) Dopaminergic modulation of highlevel cognition in Parkinson's disease: The role of the prefrontal cortex revealed by PET. Brain, 125, 584-594. doi:10.1093/brain/awf052

[33] Lewis, S.J., Dove, A., Robbins, T.W., Barker, R.A. and Owen, A.M. (2003) Cognitive impairments in early Parkinson's disease are accompanied by reductions in activity in frontostriatal neural circuitry. The Journal of Neuroscience: The Official Journal of the Society for Neuroscience, 23, 6351-6356.
[34] Lange, K.W., Robbins, T.W., Marsden, C.D., James, M., Owen, A.M. and Paul, G.M. (1992) L-dopa withdrawal in Parkinson's disease selectively impairs cognitive performance in tests sensitive to frontal lobe dysfunction. Psychopharmacology, 107, 394-404. doi:10.1007/BF02245167

[35] Lewis, S.J., Slabosz, A., Robbins, T.W., Barker, R.A. and Owen A.M. (2005) Dopaminergic basis for deficits in working memory but not attentional set-shifting in Parkinson's disease. Neuropsychologia, 43, 823-832. doi:10.1016/j.neuropsychologia.2004.10.001

[36] Moustafa, A.A, Sherman, S.J. and Frank, M.J. (2008) A dopaminergic basis for working memory, learning and attentional shifting in Parkinsonism. Neuropsychologia, 46, 3144-3156. doi:10.1016/j.neuropsychologia.2008.07.011

[37] Brookshire, B., Chapman, S., Song, J. and Levin, H. (2000) Cognitive and linguistic correlates of children's discourse after closed head injury: A three-year follow-up. Journal of the International Neuropsychological Society, 6, 741-751. doi:10.1017/S1355617700677019 